\title{
Usage of Pediatric Emergency Department for Non-Urgent Complaints
}

Raziye Dut

Clinic of Pediatrics, Health Sciences University, Süleymaniye Gynecologic-Obstetrics and Children IIness, Training and Research Hospital, Istanbul, Turkey

\begin{abstract}
Aim: The number of visits to pediatric emergency departments is increasing. To determine the epidemiological profile of patients that are being examined by a pediatrician at emergency departments (EDs) is essential for planning medical care.

Materials and Methods: 12.535 pediatric patients that had visited a pediatric emergency department (PED) due to a non-urgent complaint were enrolled. Demographic features such as gender and age; the nature of the presenting complaint; timing of the visit, i.e., frequency of the visits according to seasons, days of the week, times of the day; and other factors including admission rates, length of stay, and rates of treatment upon observation were reviewed.

Results: Of the 12.535 patients included in the study, 5645 (45.0\%) were girls, 6890 (54.9\%) were boys, and the mean age was 4.9 years old. Most patients were $1-4 \mathrm{y}(33.8 \%)$ and patients older than $15 \mathrm{y}(3.2 \%)$ were the smallest group. The results revealed that the most common complaints were fever (38.5\%), coughing (20.7\%) and vomiting (11.1\%). The inpatient admission rate was $0.69 \%$ and the rate of patients being treated upon observation was $5.9 \%$. The most common visiting times were 18:00-23:59 (42.9\%). Furthermore, $65 \%$ of visits took place during workdays and $35.0 \%$ during weekends. Most visits took place on Monday (15.5\%). The length of stay was different amongst the different age groups $(p=0.009)$.
\end{abstract}

Conclusion: Pediatric patients typically are admitted to EDs for common pediatric complaints rather than uncommon complaints or accidents. The result of the present study may be useful in the management planning of pediatric emergency departments.

Keywords: Emergency department, complaints, pediatrician

\section{Introduction}

Emergency department (ED) usage has been increasing in Turkey and in the world. Of all children in the U.S., $20 \%$ will visit an ED at least once each year $(1,2)$. Patients $\leq 18$ years old account for about $25 \%$ of the total number of ED visits (3). ED usage due to non-urgent conditions is very high (4).

The percentage of non-urgent visits to pediatric EDs (PEDs) has been identified to be $15 \%$ to $60 \%$, and from $11 \%$ to $83 \%$ in general EDs. Non-urgent ED visits are defined as visits for conditions in which a delay of several hours would not increase the likelihood of an adverse outcome, and these visits can involve admission to hospital, diagnoses, vital sign assessment, complaint, timing of visit, arrival to ED, and procedures and/or tests being ordered. These type of visits are characterized by the patient's ability to wait for evaluation or care (5). Billings et al. (6) examined data on adult emergency visits, ex- cluding visits due to injury, mental health complaints, and alcohol or substance abuse, and found that 4 to 5 visits were due to non-urgent conditions that could have otherwise been managed in a primary care setting or through preventive measures (6).

The usage of PEDs for non-urgent complaints has saturated the capacity of PEDs and is leading to excessive healthcare spending, as well as unnecessary testing and treatments, preventing the efficient and effective usage and quality of PEDs. Visiting PEDs for non-urgent concerns may unnecessarily crowd the department, leading to longer waiting times, adverse events due to delays in care and increased costs. Many of the PED visits could have been managed in a primary care setting, and this has been shown to improve health outcomes. Parents take their children to PEDs for non-urgent care because of the advantages of PED care (7).

In a study, Lowe and Abbuhl argue that social, economic, and practical factors contribute to such visits, and that the societal context of the

This study was presented at the $52^{\text {nd }}$ Congress of Turkish Pediatric Association ,15-19 May 2016, Antalya, Turkey.

Correspondence to: Raziye Dut e-mail: raziyedut@gmail.com

Received: 05.11.2016 • Accepted: 15.01.2017

(C) Copyright 2017 by Emergency Physicians Association of Turkey - Available online at www.eajem.com

DOI: $10.5152 /$ eajem.2017.63935 
visits must be assessed to determine if these visits are appropriate $(8,9)$. Sempere-Selva et al. (10) concluded that patients preferred to use PED services because of their greater convenience and accessibility. Several studies have examined PED usage with the aim of developing interventions to increase the efficiency of EDs and decrease costs (11).

Descriptive research has identified the demographic characteristics of those using PEDs for non-urgent care, as it is vital to prevent unnecessary crowding of PEDs and improve medical care.

In the present study, visits to PEDs due to non-urgent complaints were investigated in the Acıbadem Maslak Hospital, a private hospital of Istanbul, Turkey. This study was conducted to understand the causes leading to crowding in PEDs and to highlight this issue for future research, thus helping to achieve a cost-effective usage of PEDs.

\section{Materials and Methods}

Non-urgent visits to PEDs ( $<16 \mathrm{yr}$ old) were analyzed. This is a single-center, retrospective study on PED usage, which included 12.535 patients who visited a PED and were examined by a pediatrician. We particularly looked at non-urgent patients who were examined by a pediatrician to show the epidemiological characteristics of processing medical care. Informed consent is not necessary due to the retrospective nature of this study.

Data regarding patients' demographic features, complaints upon presentation, timing of the visits (season, day of the week, time of the day), inpatient admission rates, length of stay (LOS), and treatment upon observation were extracted.
We classified patients according to age, as follows: $<1 \mathrm{y}, 1-4 \mathrm{y}$, $5-9 y, 10-14 y$ and $>15 y$. We analyzed the characteristics of non-urgent visits to PEDs: 1 ) age and sex of the patient; 2 ) timing of the visits (season, day of the week, time of the day, i.e., 00:00-05:59, $06: 00-11: 59,12: 00-17: 59,18: 00-23: 59) ; 3)$ waiting times at the emergency department, i.e., time elapsed between admission and departure(discharge) ; 4) rates of treatment upon observation, admission, discharge.

We determined the number of admissions for each age group and month, and results were compared. Although the complaints could be considered as non-urgent, admission can be necessary. We also obtained data regarding non-urgent, non-vital, possible treatments at home of the emergency departments. Trauma, injury, car crash, status epilepticus, convulsion with or without fever, respiratory arrest, drug abuse, intoxication, other vital urgent conditions, and chronic and recurrent conditions were excluded.

Ethics Committee Approval was taken from Ethical Committee of Acıbadem University for this study.

\section{Statistical analysis}

The Number Cruncher Statistical System (NCSS) 2007 statistical software program (Utah, USA) was used. Descriptive statistical analysis, single direction analysis, the Tukey multiple comparative test, chisquare test, and Fisher reality test were employed. A $p$ value $<0.05$ was considered statistically significant. Data excluded from the analysis are indicated in the text and tables.

Table 1. Age groups and their presenting complaints

\begin{tabular}{|c|c|c|c|c|c|c|c|c|c|c|c|}
\hline & \multicolumn{2}{|c|}{$<1 \mathrm{y}$} & \multicolumn{2}{|c|}{$1-4 y$} & \multicolumn{2}{|c|}{$5-9 y$} & \multicolumn{2}{|c|}{$10-14 y$} & \multicolumn{2}{|c|}{$>15 y$} & \multirow[b]{2}{*}{$\mathbf{p}$} \\
\hline & $\mathbf{N}$ & $\%$ & $\mathbf{N}$ & $\%$ & $\mathbf{N}$ & $\%$ & $\mathbf{N}$ & $\%$ & $\mathbf{N}$ & $\%$ & \\
\hline Fever & 554 & 37.4 & 2712 & 43.6 & 1589 & 37.4 & 471 & 29.4 & 115 & 28.4 & $<0.001$ \\
\hline Cough & 264 & 17.8 & 1142 & 23.7 & 888 & 20.9 & 252 & 15.7 & 59 & 14.5 & $<0.001$ \\
\hline Vomiting & 120 & 8.1 & 506 & 10.5 & 527 & 12.4 & 215 & 13.4 & 34 & 8.4 & $<0.001$ \\
\hline Nausea & 9 & 0.6 & 46 & 0.9 & 117 & 2.7 & 92 & 5.7 & 44 & 10.8 & $<0.001$ \\
\hline Abdominal Pain & 10 & 0.6 & 109 & 2.2 & 335 & 7.9 & 166 & 10.3 & 34 & 8.4 & $<0.001$ \\
\hline Rash & 109 & 7.3 & 215 & 4.4 & 176 & 4.1 & 58 & 3.6 & 11 & 2.7 & $<0.001$ \\
\hline Ear Pain & 13 & 0.8 & 287 & 5.9 & 379 & 8.9 & 78 & 4.8 & 17 & 4.2 & $<0.001$ \\
\hline Headache & 2 & 0.1 & 9 & 0.1 & 66 & 1.5 & 59 & 3.6 & 19 & 4.6 & $<0.001$ \\
\hline Diarrhea & 58 & 3.9 & 213 & 4.4 & 162 & 3.8 & 83 & 5.1 & 22 & 5.4 & 0.116 \\
\hline Stomatitis & 9 & 0.6 & 29 & 0.6 & 6 & 0.1 & 3 & 0.1 & 0 & 0.0 & 0.001 \\
\hline Foot-Leg Pain & 0 & 0.0 & 15 & 0.3 & 13 & 0.3 & 3 & 0.1 & 0 & 0.0 & 0.177 \\
\hline Throat Pain & 16 & 1.0 & 157 & 3.2 & 342 & 8.0 & 183 & 11.4 & 67 & 16.5 & $<0.001$ \\
\hline Rhinorrhea & 69 & 4.6 & 240 & 4.9 & 138 & 3.2 & 46 & 2.8 & 22 & 5.4 & $<0.001$ \\
\hline Stuffiness & 32 & 2.1 & 52 & 1.0 & 26 & 0.6 & 12 & 0.7 & 4 & 0.9 & $<0.001$ \\
\hline Fatigue & 21 & 1.4 & 42 & 0.8 & 56 & 1.3 & 31 & 1.9 & 21 & 5.1 & $<0.001$ \\
\hline Urine pain & 3 & 0.2 & 39 & 0.8 & 16 & 0.3 & 3 & 0.1 & 0 & 0.0 & 0.001 \\
\hline Hyperemic Eye & 16 & 1.0 & 28 & 0.5 & 20 & 0.4 & 6 & 0.3 & 0 & 0.0 & 0.025 \\
\hline Constipation & 23 & 1.5 & 41 & 0.8 & 9 & 0.2 & 2 & 0.1 & 0 & 0.0 & 0.001 \\
\hline Restlessness & 166 & 11.2 & 59 & 1.2 & 5 & 0.1 & 1 & 0.0 & 0 & 0.0 & 0.001 \\
\hline
\end{tabular}


Table 2. Number of visits for every season, days of the week and hours of the day; observation unit care and admission for every age group

\begin{tabular}{|c|c|c|c|c|c|c|c|c|c|c|c|c|}
\hline & & \multicolumn{2}{|c|}{$<1 \mathrm{y}$} & \multicolumn{2}{|c|}{$1-4 y$} & \multicolumn{2}{|c|}{ 5-9 y } & \multicolumn{2}{|c|}{$10-14 y$} & \multicolumn{2}{|c|}{$>15 y$} & \multirow[b]{2}{*}{$\mathbf{p}$} \\
\hline & & $\mathbf{N}$ & $\%$ & $\mathbf{N}$ & $\%$ & $\mathbf{N}$ & $\%$ & $\mathbf{N}$ & $\%$ & $\mathbf{N}$ & $\%$ & \\
\hline \multirow[t]{2}{*}{ Sex } & Girl & 672 & 45.4 & 2157 & 44.8 & 1899 & 44.8 & 711 & 44.4 & 206 & 50.8 & \multirow[t]{2}{*}{0.197} \\
\hline & Boy & 808 & 54.5 & 2656 & 55.1 & 2339 & 55.1 & 888 & 55.5 & 199 & 49.1 & \\
\hline \multirow[t]{4}{*}{ Season } & Winter & 99 & 6.6 & 379 & 7.8 & 429 & 10.1 & 170 & 10.6 & 31 & 7.6 & \multirow[t]{4}{*}{$<0.001$} \\
\hline & Spring & 95 & 6.4 & 371 & 7.7 & 390 & 9.2 & 153 & 9.5 & 43 & 10.6 & \\
\hline & Summer & 407 & 27.5 & 1190 & 24.7 & 758 & 17.8 & 311 & 19.4 & 66 & 16.3 & \\
\hline & Autumn & 879 & 59.3 & 2873 & 59.6 & 2661 & 62.7 & 965 & 60.3 & 265 & 65.4 & \\
\hline \multirow[t]{7}{*}{ Visiting Day } & Monday & 243 & 16.4 & 717 & 14.9 & 652 & 15.3 & 262 & 16.3 & 70 & 17.2 & \multirow[t]{7}{*}{0.002} \\
\hline & Tuesday & 175 & 11.8 & 606 & 12.5 & 519 & 12.2 & 194 & 12.1 & 73 & 18.0 & \\
\hline & Wednesday & 190 & 12.8 & 605 & 12.5 & 474 & 11.1 & 222 & 13.8 & 51 & 12.5 & \\
\hline & Thursday & 170 & 11.4 & 574 & 11.9 & 537 & 12.6 & 198 & 12.3 & 60 & 14.8 & \\
\hline & Friday & 203 & 13.7 & 613 & 12.7 & 504 & 11.8 & 187 & 11.6 & 49 & 12.1 & \\
\hline & Saturday & 226 & 15.2 & 725 & 15.0 & 678 & 16.0 & 242 & 15.1 & 46 & 11.3 & \\
\hline & Sunday & 273 & 18.4 & 973 & 20.2 & 874 & 20.6 & 294 & 18.3 & 56 & 13.8 & \\
\hline \multirow[t]{2}{*}{ Total Day } & Workday & 981 & 66.2 & 3115 & 64.7 & 2686 & 63.3 & 1063 & 66.4 & 303 & 74.8 & \multirow[t]{2}{*}{$<0.001$} \\
\hline & Weekend & 499 & 33.7 & 1698 & 35.2 & 1552 & 36.6 & 536 & 33.5 & 102 & 25.1 & \\
\hline \multirow[t]{4}{*}{ Visiting Hours } & 00:00-05:59 & 205 & 13.9 & 561 & 11.7 & 375 & 8.9 & 120 & 7.5 & 33 & 8.2 & \multirow[t]{4}{*}{$<0.001$} \\
\hline & $06: 00-11: 59$ & 223 & 15.1 & 913 & 19.1 & 804 & 19.1 & 317 & 20.0 & 78 & 19.5 & \\
\hline & $12: 00-17: 59$ & 343 & 23.3 & 1239 & 25.9 & 1251 & 29.7 & 490 & 30.9 & 105 & 26.2 & \\
\hline & 18:00-23:59 & 698 & 47.5 & 2066 & 43.2 & 1780 & 42.2 & 658 & 41.5 & 184 & 46.0 & \\
\hline \multicolumn{2}{|c|}{ Observation Unit care } & 90 & 6.0 & 280 & 5.8 & 251 & 5.9 & 95 & 5.9 & 25 & 6.1 & 0.976 \\
\hline \multicolumn{2}{|l|}{ Admission } & 24 & 1.6 & 31 & 0.6 & 26 & 0.6 & 4 & 0.2 & 1 & 0.2 & $<0.001$ \\
\hline
\end{tabular}

\section{Results}

\section{Demographic data}

We studied 12.535 patients, of which 5645 (45.0\%) were girls and 6890 (54.9\%) were boys, with a median age of 4.9 years old. Of the patients, 1480 (11.8\%) were <1y, 4813 (38.4\%) were 1-4y, 4238 (33.8\%) were $5-9 y, 1599$ (12.8\%) were $10-14 y$, and 405 (3.2\%) were $>15 y$. No difference was found between girls and boys in terms of age distribution $(p=0.197)$.

\section{Presenting complaints}

The most common complaints upon presentation at the PED were fever (38.5\%), cough (20.7\%), and vomiting (11.1\%). Coughing was more common in boys $(\mathrm{p}=0.001)$. Vomiting, ear pain, and throat pain was more common in girls $(p=0.018),(p=0.023),(p=0.006)$, respectively.

Complaints upon presentation according to age are shown in Table 1. Fever was more common among 1-4y than in the other age groups ( $p=0.0001)$. Coughing was less frequent in those $<1 y$ and $>15 y$ compared to the other age groups $(p=0.0001)$. In the $>15 y$ group, nausea was more common than in the other age groups $(p=0.0001)$. In the $<1 y$ and 1-4y groups, abdominal pain was less common compared to the other age groups $(p=0.0001)$. When compared to the other age groups, in the $10-14 y$ and $>15 y$ groups, the incidence of rash was lower $(p=0.0001)$, but headache was more common $(p=0.0001)$. In the $<1 y$ group the incidence of ear pain was lower than in the other age groups $(p=0.0001)$. Incidence of diarrhea was not different amongst the age groups $(p=0.116)$. Stomatitis was not found in the $>15 y$ group, $(p=0.0001)$. Throat pain was less common for the $<1 y$ and $1-4 y$ groups compared to the other age groups $(p=0.0001)$. Rhinorrea was less frequent in the 5-9y and 10-14y groups compared to the other age groups $(p=0.0001)$. Stuffiness was more common in the $<1 y$ and $1-4 y$ groups than in the other age groups $(p=0.0001)$. Fatigue was more common in the $>15 y$ than in other age groups $(p=0.0001)$. Complaints of painful urination, constipation, and restlessness were less common in the $>15 y$ group than in the other age groups ( $p=0.0001)$. Incidence of dyspnea was not different amongst the $<1 y, 1-4 y, 5-9 y, 10-14 y$, and $>15 y$ groups $(p=0.153)$. Restlessness was more common in the $<1 y$ group $(p=0.0001)$.

\section{Length of stay (LOS)}

In the studied PED visits, there was no difference in the LOS between girls and boys $(p=0.246)$. However, LOS was different between the age groups $(p=0.009)$. The length of stay for the $<1 y$ was longer than for the 1-4y $(p=0.0001)$ and the $5-9 y(p=0.01)$, but there was no difference between the other age groups ( $p>0.05)$ and there was no difference between seasons ( $p=0.0001$ ); however, in winter, LOS was longer than in spring $(p=0.002)$ or autumn $(p=0.0001)$. 
Table 3. Visiting hours and presenting complaints

\begin{tabular}{|c|c|c|c|c|c|c|c|c|c|}
\hline \multirow{2}{*}{$\begin{array}{l}\text { Visiting Hours/Presenting } \\
\text { Complaints } \\
\text { Fever }\end{array}$} & \multicolumn{2}{|c|}{ 00:00-05:59 } & \multicolumn{2}{|c|}{ 06:00-11:59 } & \multicolumn{2}{|c|}{ 12:00-17:59 } & \multicolumn{2}{|c|}{ 18:00-23:59 } & \multirow{2}{*}{$\begin{array}{c}\mathbf{p} \\
0.192\end{array}$} \\
\hline & 512 & $39.57 \%$ & 891 & $38.16 \%$ & 1275 & $37.19 \%$ & 2.118 & $39.32 \%$ & \\
\hline Cough & 193 & $14.91 \%$ & 559 & $23.94 \%$ & 826 & $24.10 \%$ & 1.003 & $18.62 \%$ & $<0.001$ \\
\hline Vomiting & 234 & $18.08 \%$ & 284 & $12.16 \%$ & 336 & $9.80 \%$ & 539 & $10.01 \%$ & $<0.001$ \\
\hline Nausea & 26 & $2.01 \%$ & 73 & $3.13 \%$ & 83 & $2.42 \%$ & 122 & $2.27 \%$ & 0.097 \\
\hline Abdominal Pain & 79 & $6.11 \%$ & 127 & $5.44 \%$ & 164 & $4.78 \%$ & 278 & $5.16 \%$ & 0.304 \\
\hline Rash & 34 & $2.63 \%$ & 97 & $4.15 \%$ & 151 & $4.40 \%$ & 282 & $5.24 \%$ & $<0.001$ \\
\hline Ear Pain & 119 & $9.20 \%$ & 132 & $5.65 \%$ & 172 & $5.02 \%$ & 349 & $6.48 \%$ & $<0.001$ \\
\hline Headache & 11 & $0.85 \%$ & 26 & $1.11 \%$ & 42 & $1.23 \%$ & 75 & $1.39 \%$ & 0.401 \\
\hline Diarrhea & 55 & $4.25 \%$ & 130 & $5.57 \%$ & 133 & $3.88 \%$ & 216 & $4.01 \%$ & 0.008 \\
\hline Stomatitis & 3 & $0.23 \%$ & 6 & $0.26 \%$ & 18 & $0.53 \%$ & 20 & $0.37 \%$ & 0.305 \\
\hline Foot-Leg Pain & 8 & $0.62 \%$ & 2 & $0.09 \%$ & 8 & $0.23 \%$ & 13 & $0.24 \%$ & 0.022 \\
\hline Throat Pain & 24 & $1.85 \%$ & 144 & $6.17 \%$ & 262 & $7.64 \%$ & 325 & $6.03 \%$ & $<0.001$ \\
\hline Rhinorrhea & 23 & $1.78 \%$ & 100 & $4.28 \%$ & 170 & $4.96 \%$ & 221 & $4.10 \%$ & $<0.001$ \\
\hline Stuffiness & 10 & $0.77 \%$ & 27 & $1.16 \%$ & 37 & $1.08 \%$ & 49 & $0.91 \%$ & 0.590 \\
\hline Fatique & 9 & $0.70 \%$ & 24 & $1.03 \%$ & 48 & $1.40 \%$ & 87 & $1.62 \%$ & 0.031 \\
\hline Urine Pain & 3 & $0.23 \%$ & 7 & $0.30 \%$ & 17 & $0.50 \%$ & 34 & $0.63 \%$ & 0.127 \\
\hline Hyperemic Eye & 1 & $0.08 \%$ & 14 & $0.60 \%$ & 25 & $0.73 \%$ & 29 & $0.54 \%$ & 0.061 \\
\hline Constipation & 8 & $0.62 \%$ & 8 & $0.34 \%$ & 16 & $0.47 \%$ & 43 & $0.80 \%$ & 0.068 \\
\hline Restlessness & 66 & $5.10 \%$ & 16 & $0.69 \%$ & 34 & $0.99 \%$ & 112 & $2.08 \%$ & $<0.001$ \\
\hline
\end{tabular}

\section{Season/day/admission/observation}

Of the 12.535 patients, $86(0.69 \%)$ were admitted and 741 (5.9\%) were treated upon observation.

No differences were found between girls and boys as regards presentation to the PED with respect to season $(p=0.266)$, day of the week $(p=0.850)$, workday and weekend $(p=0.929)$, time of the day $(p=0.504)$, admission rates $(p=0.553)$, and rates of treatment upon observation $(p=0.226)$.

Presentation rates according to season, day of the week, time of the day, rates of treatment upon observation, and admission rates are shown in Table 2.

The number of visits to the PED in summer was higher for the $<1 y$ and $1-4 y$ groups compared to the other age groups $(p=0.0001)$. There were less visits to the PED on weekends for the $>15 y$ group compared to the other age groups $(p=0.0001)$.

There was no difference in the rates of treatment upon observation amongst the age groups $(p=0.976)$. Admission rates for the $<1 y$ were higher compared to the other age groups $(p=0.0001)$.

Treatment rates upon observation were lower in spring than in the other seasons $(p=0.0001)$. There were no admissions in spring $(p=0.001)$. For the $<1 y$ group, the number of visits in summer and autumn was higher than in the other seasons $(p=0.0001)$. There were less visits during winter workdays $(\mathrm{p}=0.0001)$. There were less visits during the 12:00-17:59 time slot in summer than in other seasons $(p=0.0001)$. Fever was the most common complaint in autumn compared to the other seasons $(p=0.0001)$.

\section{Visiting times}

For any given day of the week, the most common, visits took place during the 18:00-23:59 time slot (42.9\%), followed by 12:0017:59 (27.3\%), 06:00-11:59 (18.6\%), and 00:00-05:59 (10.3\%).

are shown in Table 3. Restless, vomiting and ear pain were more common at 00:00-05:59 compared to other times of the day $(p=0.0001)$, $(p=0.0001),(p=0.0001)$, respectively. Coughing and throat pain were less common complaints during the 00:00-05:59 time slot compared to other times of the day $(p=0.0001),(p=0.0001)$, respectively.

For the $<1 y$ and 1-4y groups, there were more visits during the 00:00-05:59 times, compared to the other age groups $(p=0.0001)$.

\section{Discussion}

Pediatric emergency departments are commonly used by pediatric patients due to non-urgent reasons, which could have been managed by their primary care provider. Often, pediatric patients visit PEDs during days and hours in which the primary care pediatric centers are closed, particularly on the weekends and in the evenings (12).

The Healthcare Cost and Utilization Project (Agency for Healthcare Research and Quality) categorizes the top 10 reasons for PED visits as the same top 10 reasons for visits to primary care centers. This suggests that these conditions could be appropriately cared for in a primary care setting (13). A publication on PEDs shows that one third of pediatric patients visit PEDs for observation and treatment of common illnesses (14). 
In that study, of all children visiting PEDs, 54.9\% were boys and the most common age group was 1-4y. For children under one year old, immunization scale is very hard and routine control at primary care is more common. But after one year, immunization scale is not that hard and routine controls are becoming not frequently. These findings agree well with the literature. In the literature, the age group that visited PEDs the most was the 1-4y group (42.3\%); of those children, $59.1 \%$ were boys (15). Many authors found age as a predictor for inappropriate ED visits (7, 16-19). Detailed clinical, familial and social data are needed to determine the true reasons for frequent visits to PEDs in this age group. The neonatal period $(<28$ days old) is a vulnerable period of pediatric health where emergencies can certainly occur. For newborns, hospital care after birth and early primary care may have a significant impact on healthcare service usage. We investigated this group into $<1 y$, did not assess them seperately.

It is known that $10-19 y$ period is considered as adolescent period. In Turkey, children $\leq 16 y$ are examined at pediatric clinics and PEDs. Pediatric physicians should understand their psychosocial requirements, and discuss HEADSS (Home, Education/Employment, Activity, Drugs, Sexuality, Suicide) assessment topics. Adolescents do not bring up complaints easily, so trust is more important for them. They contact their primary care provider more than PEDs, and in practice on how to specifically provide for the unique needs of this age population $(20,21)$. Adolescents who visit PEDs due to non-urgent complaints are a vulnerable group and are more likely to report urgent concerns such as drug use/abuse, suicide, unintentional injuries, or crashes (22). In that study, non-urgent complaints were found. Fatique and headache were more common in the adolescent group.

The rate of admission was $0.69 \%$, and the rate of treatment upon observation was $5.9 \%$. These results show that patients who visit PEDs are usually discharged. The lower admission rate and higher rate of treatment upon observation suggests that PEDs have a higher workload for hospitals. One of the most important functions of an emergency department is to assess patient status so as to categorize the patient as inpatient or outpatient. With rapid, appropriate assessment of patient status, the incidence of emergency department overcrowding can also be reduced, thereby reducing treatment delay and mortality (23-25).

Observation unit care for pediatric short-course treatments (typically $<24$ hours) and frequent reassessments are very important, as using inpatient beds for short-stay patients may delay the admission for children requiring a longer inpatient stay. Another advantage of the observation unit is the lower cost of care $(26,27)$.

Overall, workday visits were the most common (65.0\%), followed by weekend visits (35.0\%). The number of visits to PEDs was higher on Mondays (15.5\%) than on the other workdays. Regarding visits to PEDs on weekends, the number of visits on Sunday (19.7\%) was higher than on Saturday (\%). Overall, visits to PEDs on Sunday ED were the most common. In the literature, visits to PEDs on Sunday are reported to be $23.7 \%$, which is similar to the result for this study (15).

Complaints differed according to season and the number of visits during different seasons differed according to age group. In winter, the LOS in PEDs was longer than in spring and autumn, but did not differ from summer. Overall, the number of non-urgent visits is high during autumn. This needs to be investigated to understand the nature of the diagnoses according to the seasons and the national data on viral or allergic diseases.
We found that complaints were different depending on the time of the PED visit. Visits to PEDs most commonly occurred during 18:00-23:59 (42.9\%). Visits during 00:00-05:59 were more frequent for the $<1 \mathrm{y}$ and $1-4 \mathrm{y}$ groups. This probably reflects higher anxiety and need for reassurance in parents.

A 2006 study from the State Children's Health Insurance Program of New York City suggested that during daytime hours, only $20 \%$ of parents brought their children to PEDs because of the perceived need of hospitalization, i.e., care that could not be provided in a primary care setting (28). Generally, a pediatrician or a general practitioner in a primary care center is available during office hours, from 8 A.M to 6 P.M during workdays and from 9 A.M to 2 P.M on Saturdays. Many parents who seek outpatient treatment care during the evening hours prefer to take their children to a pediatrician in a primary care center, but visit a PED because of the lack of primary care access during those hours. The idea that extended office hours in primary care settings can reduce ED usage has recently been raised in studies with adult patients (29). This idea may be applicable for pediatric patients so as to receive a higher quality of care. Thus, after-hour pediatric services could reduce PED usage. The effect of extended hours in pediatric primary care clinics on PED usage (with respect to season, timing of after-hour visits, age of patients, presenting complaint, parent perceptions, and preferences for emergency care) should be evaluated.

Parents often overestimate the severity of their child's condition as urgent; parents need to be educated by physicians, as most of the pediatric conditions can be prevented. When illnesses arise, only a few are genuinely urgent conditions; thus, illnesses may be acute but usually do not require an extensive all-inclusive treatment at a PED.

Furthermore, this study would be a reference for upcoming research aimed at studying why parents visit PEDs so frequently, and highlights the importance of reducing PED usage due to non-urgent complaints.

\section{Study limitations}

This study has certain limitations. It included only one private hospital in Istanbul, such that the results cannot be readily generalized. Thus, there may be variation in the reasons for non-urgent pediatric care in other PEDs and other regions of the country. It will be important to examine the trends of other public hospitals in future studies.

\section{Conclusion}

The present study described the demographic features, complaints, and seasonal and time patterns of visits to PEDs for pediatric examination due to non-urgent complaints. The results revealed that typically, pediatric patients visit PEDs due to common pediatric complaints rather than uncommon complaints or accidents. This leads to an increased number of visits, which in turn leads to longer waiting times, causing patient dissatisfaction. Overcrowding also cause many patients to leave the PED without having been examined by a physician. So, a combination of high patient volumes and limited emergency care capabilities represent a serious problem. Monitoring of frequent visits to PEDs may have the potential to be useful as a quantitative marker for patient health and/or quality of health care delivery. Most PED visits could have been managed by the primary care provider (PCP). Access to primary care/preventative care and 
providing parental education about how to address childhood illnesses have all been associated with a decreased number of visits to PEDs due to non-urgent complaints. The future investigations to exclude why parents come children to PED with non-urgent conditions would be planned. Also, parents should be trained about urgent and non-urgent conditions to reduce PED overcrowding and improve cost efficiency.

Ethics Committee Approval: Ethics committee approval was received for this study from the ethics committee of Acıbadem University (Decision No: 2014-571).

Informed Consent: Informed consent is not necessary due to the retrospective nature of this study.

Peer-review: Externally peer-reviewed.

Acknowledgements: The author would like to thank all of the nurses and health care workers of Acıbadem Maslak Hospital, Emergency Department.

Conflict of Interest: No conflict of interest was declared by the authors.

Financial Disclosure: The authors declared that this study has received no financial support.

\section{References}

1. Alpern ER, Clark AE, Alessandrini EA, Gorelick MH, Kittick M, Stanley RM, et al. Recurrent and high-frequency use of the emergency department by pediatric patients. Acad Emerg Med 2014; 21: 365-73. [CrossRef]

2. Alpern ER, Stanley RM, Gorelick MH, Donaldson A, Knight S, Teach SJ, et al. Epidemiology of a pediatric emergency medicine research network: the PECARN Core Data Project. Pediatr Emerg Care 2006; 22: 689-99. [CrossRef]

3. Mistry RD, Cho CS, Bilker WB, Brousseau DC, Alessandrini EA. Categorizing urgency of infant emergency department visits: agreement between criteria. Acad Emerg Med 2006; 13: 1304-11. [CrossRef]

4. Vedovetto A, Soriani N, Merlo E, Gregori D. The burden of inappropriate emergency department pediatric visits: why Italy needs an urgent reform. Health Serv Res 2014; 49: 1290-305. [CrossRef]

5. Uscher-Pines L, Pines J, Kellermann A, Gillen E, Mehrotra A. Emergency department visits for nonurgent conditions: systematic literature review. Am J Manag Care 2013; 19: 47-59.

6. Billings J, Parikh N, Mijanovich T. Emergency department use in New York City: a survey of Bronx patients. Issue Brief (Commonw Fund) 2000; (435): 1-5.

7. Berry A, Brousseau D, Brotanek JM, Tomany-Korman S, Flores G. Why do parents bring children to the emergency department for nonurgent conditions? A qualitative study. Ambul Pediatr 2008; 8: 360-7. [CrossRef]

8. Chin NP, Goepp JG, Malia T, Harris L, Poordabbagh A. Nonurgent use of a pediatric emergency department: a preliminary qualitative study. Pediatr Emerg Care 2006; 22: 22-7. [CrossRef]

9. Lowe RA, Abbuhl SB. Appropriate standards for "appropriateness" research. Ann Emerg Med 2001; 37: 629-32. [CrossRef]

10. Sempere-Selva T, Peiró S, Sendra-Pina P, Martínez-Espín C, López-Aguilera I. Inappropriate use of an accident and emergency department: magnitude, associated factors, and reasons--an approach with explicit criteria. Ann Emerg Med 2001; 37: 568-79. [CrossRef]

11. Mistry RD, Hoffmann RG, Yauck JS, Brousseau DC. Association between parental and childhood emergency department utilization. Pediatrics 2005; 115: e147-51. [CrossRef]

12. Hummel K, Mohler MJ, Clemens CJ, Duncan B. Why parents use the emergency department during evening hours for nonemergent pediatric care. Clin Pediatr (Phila) 2014; 53: 1055-61. [CrossRef]

13. Merrill $\mathrm{CT}$, Owens $\mathrm{PL}$, Stocks $\mathrm{C}$. Pediatric emergency department visits in community hospitals from selected states, 2005: Statistical brief \#52. Healthcare Cost and Utilization Project (HCUP) Statistical Briefs. Rockville (MD) 2006.

14. Scribano PV, Wiley JF 2nd, Platt K. Use of an observation unit by a pediatric emergency department for common pediatric illnesses. Pediatr Emerg Care 2001; 17: 321-3. [CrossRef]

15. Kwak YH, Kim DK, Jang HY. Utilization of emergency department by children in Korea. J Korean Med Sci 2012; 27: 1222-8. [CrossRef]

16. Carret ML, Fassa AG, Kawachi I. Demand for emergency health service: factors associated with inappropriate use. BMC Health Serv Res 2007; 7: 131 [CrossRef]

17. Ben-Isaac E, Schrager SM, Keefer M, Chen AY. National profile of nonemergent pediatric emergency department visits. Pediatrics 2010; 125: 454-9. [CrossRef]

18. Davis JW, Fujimoto RY, Chan H, Juarez DT. Identifying characteristics of patients with low urgency emergency department visits in a managed care setting. Manag Care 2010; 19: 38-44.

19. Brousseau DC, Nimmer MR, Yunk NL, Nattinger AB, Greer A. Nonurgent emergency-department care: analysis of parent and primary physician perspectives. Pediatrics 2011; 127: e375-81. [CrossRef]

20. Hicks CF, Ward MJ, Platt SL. Adolescents' and young adults' perspectives on their emergency care. Pediatr Emerg Care 2014; 30: 529-33. [CrossRef]

21. Pitts SR, Niska RW, Xu J, Burt CW. National hospital ambulatory medical care survey: 2006 emergency department summary. Natl Health Stat Report 2008; 7: 1-38.

22. Wilson KM, Klein JD. Adolescents who use the emergency department as their usual source of care. Arch Pediatr Adolesc Med 2000; 154: 361-5. [CrossRef]

23. Weiss SJ, Ernst AA, Sills MR, Quinn BJ, Johnson A, Nick TG. Development of a novel measure of overcrowding in a pediatric emergency department. Pediatr Emerg Care 2007; 23: 641-5. [CrossRef]

24. Chamberlain JM, Patel KM, Pollack MM. Association of emergency department care factors with admission and discharge decisions for pediatric patients. J Pediatr 2006; 149: 644-9. [CrossRef]

25. Chaiyakulsil C, Pandee U. Validation of pediatric early warning score in pediatric emergency department. Pediatr Int 2015; 57: 694-8. [CrossRef]

26. Conners GP, Melzer SM, Committee on Hospital Care, Committee on Pediatric Emergency Medicine, Betts JM, Chitkara MB, et al. Pediatric observation units. Pediatrics 2012; 130: 172-9. [CrossRef]

27. Cator AD, Weber JS, Lozon MM, Macy ML. Effect of using pediatric emergency department virtual observation on inpatient admissions and lengths of stay. Acad Pediatr 2014; 14: 510-6. [CrossRef]

28. Stockwell MS, Findley SE, Irigoyen M, Martinez RA, Sonnett M. Change in parental reasons for use of an urban pediatric emergency department in the past decade. Pediatr Emerg Care 2010; 26: 181-5. [CrossRef]

29. Göransson KE, De Waern M, Lindmarker P. Patients' pathway to emergency care: is the emergency department their first choice of care? Eur J Emerg Med 2013; 20: 45-50. [CrossRef] 